\title{
Nuevo mapa conceptual para el constitucionalismo crítico. Comentario a Albert Noguera, La ideología de la soberanía. Hacia una reconstrucción emancipadora del constitucionalismo
}

(2019) Trotta

Madrid, 168 pp.

\author{
Sebastián Martín \\ Universidad de Sevilla \\ ORCID ID 0000-0003-0142-2611 \\ sebasmartin@us.es
}

\section{Cita recomendada:}

Martín, S. (2020). Nuevo mapa conceptual para el constitucionalismo crítico. Comentario a Albert Noguera, La ideología de la soberanía. Hacia una reconstrucción emancipadora del constitucionalismo. Eunomía. Revista en Cultura de la Legalidad, 19, pp. 552-578.

doi: https://doi.org/10.20318/eunomia.2020.5730

Recibido / received: 27/08/2020

\section{Modelo}

En una alocución dirigida a los asistentes a la Cumbre de los pueblos de Québec en abril de 2001, convocada en protesta contra la paralela Cumbre de las Américas y sus planes de liberalización del comercio internacional en el continente americano, Pierre Bourdieu alentaba la sublevación popular contra una «globalización que se nos presenta como fatalidad», pero que «es efectivamente una política» (Bourdieu, 2001a, p. 566).

Se trataba de combatir una estrategia deliberada, técnicamente bien trabada y sólidamente fundada en su vertiente cultural debido al respaldo mediático oficial. La globalización a la que había que enfrentarse resultaba así, en primer término, una "política» dirigida a «imponer las condiciones más favorables a las fuerzas económicas» destruyendo nuestros "sistemas de defensa inmunitaria», es decir, transformando «en mercancías y en fuente de beneficio todas las actividades de servicio, incluidas las que responden a las necesidades fundamentales como la educación, la cultura y la sanidad». A su vez, y en consecuencia, la globalización 
aparecía a ojos de Bourdieu como «una política de despolitización», orientada a eliminar cualquier tipo de obstáculo normativo, fiscalizador o democrático al desenvolvimiento de "las fuerzas económicas y sociales así "liberadas"» (Bourdieu, 2001a, pp. 567 y 569).

Si la globalización instituía un proceso planificado que combinaba en una espiral de retroalimentación la mercantilización progresiva de todas las esferas sociales, y la desregulación paulatina -o la creciente privatización de las reglas y estándares- de los intercambios, el único modo eficaz de enfrentarse a ella era promoviendo una repolitización que combinase el pensamiento científico crítico y la acción coordinada de movimientos sociales y sindicatos. La principal novedad de este deseable ascenso repolitizador, al menos respecto de las anteriores luchas por los derechos, era que debía colocarse «más allá de las fronteras del Estado nacional» (Bourdieu, 2001a, p. 569), planteando una contestación transnacional a un desafío precisamente global.

El reto abarcaba los tratados de libre comercio suscritos entre estados americanos, pero también la evolución economicista cada vez más notoria de la integración europea, donde la «social-democracia convertida al neoliberalismo» promovía sin pudor "la desregulación salvaje», el dogma de la libre competencia y la consiguiente frustración de «la Europa social» (Bourdieu, 2000, p. 559). Solo cabía hacer frente a semejante desafío a través de un «movimiento social europeo» y también mundial.

Lo que distingue la reflexión práctica de Bourdieu es el modo en que se interrogó acerca del papel que debía desempeñar el intelectual -o, mejor dicho, el «investigador»- en la articulación e impulso de dicho movimiento social general. Preconizando el compromiso de los intelectuales con las luchas emancipadoras, desde bien pronto se mostró prevenido contra el «revolucionarismo verbal» «ideología jacobina», lo llamaba- que, en secreta complicidad con el conservadurismo, tenía la habilidad de servir para que las cosas no se inmutasen y para «dispensar de examinar el funcionamiento» del sistema sometido a crítica radical (Bourdieu, 1966, p. 70). Frente a dicha "crítica "decisionista"» o «voluntarista» regida por la inmediatez del encargo o por los apremios de la militancia, Bourdieu se adhirió a otra forma de crítica, ligada estrechamente a la investigación social, orientada al desenmascaramiento de las prácticas sigilosas de dominación e involucrada, por tanto, en «la construcción del objeto» que sometía a escrutinio (Bourdieu, 1975, p. 121).

Practicando una sociología enderezada al desvelamiento de «los resortes» a menudo encubiertos- "de la autoridad» (Bourdieu, 1982, p. 213), nuestro autor abogaba por una implicación de los intelectuales en las luchas políticas marcada por su competencia para suministrar un refinado "conocimiento del mundo social», presupuesto de cualquier acción colectiva transformadora. Cierto es que, ante la "formidable crisis de la representación» que ya se atravesaba en la Francia de los 1990, su reivindicación consistía en «reafirmar el papel del Estado», exigiéndole «que ejer[ciese] la acción reguladora capaz de contrarrestar la "fatalidad" de los mecanismos económicos», con sus disolventes consecuencias para el cuerpo social (Bourdieu, 1992, pp. 299 y 302). Sin embargo, no nos interesa tanto examinar los contornos de las alternativas que entonces postulaba cuanto el papel que asignaba a los intelectuales en su preparación.

Se puede inferir que si la respuesta que planteaba ante el deterioro de la representación era un reforzamiento del Estado regulador, capaz de restaurar las expectativas socioeconómicas legítimas de los ciudadanos, la misión que en ello 
habría de jugar el investigador era esencial: solo conociendo con cierta exactitud las regularidades sociales podrían modificarse para mejor a través del derecho y la intervención administrativa. Pero su visión del compromiso político de los intelectuales iba más allá, y se caracterizaba por la lucidísima superación de la «alternativa clásica» entre el investigador autónomo, consagrado a la ciencia pura y refractario a toda contaminación política, y el pensador militante, marcado por su compromiso partidario (Bourdieu, 1989, p. 322). Mientras que la interpretación convencional veía ambas posibilidades como mutuamente excluyentes, Bourdieu las entendía profundamente co-implicadas.

En efecto, «la dicotomía entre scholarship y commitment», entre el trabajo intelectual elaborado con arreglo a pautas científicas rigurosas o el realizado en función del compromiso político, resultaba, a su juicio, una falsedad interesada. Su convicción era que había «que ser un sabio autónomo que trabaje según las reglas del scholarship para poder producir un saber comprometido» capaz de veras de transformar las cosas (Bourdieu, 2001b, p. 572). Esto le colocaba frente a dos especímenes culturales nada infrecuentes, los de «la renuncia» y «la colaboración» (Bourdieu, 1997, p. 438): representada la primera por aquellos que pretenden huir «hacia la pureza» en la vana pretensión de ser «doblemente sabios porque no hacen nada con su ciencia» (Bourdieu, 2001b, p. 572); y encarnada la segunda, en especial, por los "doxósofos, sabios aparentes y sabios de la apariencia», según Platón, quienes, "fracasados» e incapaces "de tener éxito según las normas del campo», pontifican en público sirviéndose de su estatuto profesional y al servicio siempre de ciertos intereses corporativos o partidarios (Bourdieu, 1989, p. 332-333). Si la pretensión de pureza de los primeros amputaba la indispensable función práctica de la ciencia social, la superficialidad complaciente con el poder de los segundos pretendía borrar la evidencia de que «la fuerza específica del intelectual, incluso en política, descansa sobre la autonomía que da la capacidad de responder a las exigencias internas del campo»-0 «de la comunidad de sabios»- al que pertenece y donde trabaja (Bourdieu, 1989, p. 333).

Cuando el investigador aspira a una obra políticamente eficaz en sentido crítico, y no a una impotente caja de resonancia de las posiciones del grupo en que milita, el primer requisito entonces a cumplir es el severo adiestramiento en la disciplina que se cultiva, el resuelto manejo de la arquitectura conceptual y de los nudos problemáticos que todo saber comporta. Una primera causa en la que ha de militar es, en consecuencia, la del combate por «la autonomía del propio campo» frente a las múltiples «formas de mecenazgo» que amenazan con subordinarlo a las directrices tecnocráticas o empresariales (Bourdieu, 1989, p. 329). Y, en el terreno político, el modelo personal de referencia que estamos invocando no tuvo dudas de que su ciencia, la sociología, por exigencia humanista y racional, debía librar la batalla contra el imperialismo colonialista, contra «la dominación masculina», contra las múltiples formas de subyugación clasista y desde luego, a partir de los años 1980, contra el "neoliberalismo», entendido como una "revolución conservadora» cuyo destino fatal era el imperio de «la ley del más fuerte» (Bourdieu, 1997, p. 435).

Este convencimiento le hizo colocarse desde bien pronto al lado de los movimientos estudiantiles que rechazaban que el «patrón vanguardista», el emprendedor versátil, fuese "el ideal humano propuesto a la juventud» (Bourdieu, 1986, p. 261). Cuando era denuncia propia de minorías acusadas de aguafiestas, ya señalaba «el paro de masas», «la precariedad» rampante, «la inseguridad permanente» que azotaba también a «las capas medias», el "desmoronamiento de las solidaridades elementales, especialmente familiares», y, en fin, el "estado de anomia» a que el laissez-faire estaba condenando a las sociedades con su "guerra total contra toda la civilización asociada al Estado social» (Bourdieu, 1997, p. 437). Y 
ya entonces, aspirando a esa síntesis de «scholarship with commitment», e inspirándose en Ernst Bloch, propuso a los intelectuales críticos «restaurar un pensamiento utopista», pero ajeno al "voluntarismo puro», entrañando más bien el deber de «trabajar colectivamente en análisis ajustados a los procesos objetivos del orden que aspiran a transformar» (Bourdieu, 1997, p. 439).

\section{Confesión y esquema}

He querido comenzar glosando la figura de Pierre Bourdieu porque la considero un modelo normativo de valor excepcional cuando se trata de conciliar ciencia social y compromiso político transformador (Martín, 2014b). No puedo dejar de confesar, de entrada, en forma de franco autoanálisis, que la impronta que ha recorrido mi dedicación investigadora ha sido, principalmente, la vocación weberiana por el conocimiento puro. Aún recuerdo cuando un conocido constitucionalista, hoy diputado, me preguntó, en relación a mi libro sobre el campo de la ciencia jurídicopolítica en la II República (Martín, 2011), «qué finalidad perseguía con aquella investigación», a lo que, algo perplejo, solo pude responder que «conocer con precisión las reglas de producción del saber jurídico-constitucional en la España republicana», mas sin perseguir ulteriores funciones políticas de carácter práctico en el presente.

No obstante, ya entonces, ese afán de conocimiento sin mediación política actual partía de principios éticos, elevados a cánones epistemológicos, bien ostensibles, convenientemente explicitados y acaso identificables con los propios del constitucionalismo garantista, social y democrático (v. gr. Martín, 2007, 2009). Con mayor madurez hoy, y por las razones aducidas, concibo la disciplinada sumisión a las reglas del arte histórico-jurídico como un gesto de defensa de la autonomía del saber que practico frente a toda forma de colonización, incluso la política de procedencia progresista (Martín, 2016a). Sin embargo, el creciente peso determinante de las representaciones históricas en la orientación de las acciones colectivas, el difundido convencimiento de que los pasados de opresión sin reparar no dejan nunca de pasar (Martín, 2019), así como la constatación de que las mejores luchas emancipadoras han requerido siempre operar en determinadas constelaciones tradicionales (Martín, 2020), a cuya identificación y síntesis sirve la historiografía, me han llevado a reconocer la politicidad insorteable de la materia que investigo.

Pero en esta singladura personal, apretadamente expuesta, se ha seguido manteniendo incólume el ejemplo de referencia encarnado por Bourdieu, tan alérgico al «activismo por el activismo» como a la ciencia al servicio de la dominación. Si lo he traído a colación desde un comienzo -se habrá adivinado ya- es porque las páginas que siguen habrán de dedicarse a comentar un libro que desde su propio título confiesa que realiza ciencia jurídica para servir a propósitos emancipadores. Y no se me ocurre mejor parámetro de valoración que aquel que indica que, para servir a dicho fin liberador, debe comenzarse por practicar con maestría la propia disciplina. Anticipemos que, a mi juicio, no solo estamos ante un raro caso de capacidad constructiva y desenvolvimiento sintético en la complejidad, sino también ante un ejemplo de teorización omnicomprensiva francamente escaso, por lo que alcanzo a conocer, en la mayoritariamente formalista, exegética y sectorial ciencia española del derecho constitucional.

La satisfacción de entrada del modelo de referencia que sirve a este recensor no le exonera, en cambio, de la realización de algún comentario crítico. Para que el lector pueda ubicarlos correctamente se procederá a un resumen del trabajo en cuestión, distinguiendo, para evitar enojosas duplicaciones, los propósitos del autor y lo que considero sus aportaciones más señeras. Se continuará señalando lo que se 
ha entendido como flaquezas, ya sean de pulsación de la realidad, de soporte metodológico, de trabazón argumental o de traslado a la práctica, que, sin menoscabar el valor del conjunto, acaso le resten algo de compacidad. Y, por último, pero ya más en el sector de mi especialidad que en el de la ciencia jurídicoconstitucional, se detectarán algunas fallas en las representaciones sobre el pasado político que sirven al autor para sustentar su relato crítico de actualidad.

\section{Síntesis}

\subsection{Propósitos}

Con su habitual capacidad de diagnóstico, contaba Pierre Rosanvallon que, comenzado el presente siglo, la democracia se veía atravesada por «una contradicción esencial»: la que contrapone la aspiración de los ciudadanos «a hacerse cargo cada vez más directamente de su existencia» y su «demanda incrementada de política» e intervencionismo justo para poder «dominar un destino compartido». Creo que el libro de Albert Noguera se sitúa de lleno en esta significativa disyuntiva entre la "aspiración a más pluralismo y descentralización», con el refuerzo consiguiente "de los contrapoderes», y la «búsqueda de un lugar central en el cual pueda expresarse y corporizarse una voluntad común eficaz» (Rosanvallon, 2007, p. 11).

El autor reconoce implícitamente la posición sociológica desde la que escribe: la del «intelectual» justo en el momento histórico en el que la mayor parte de los intelectuales forma parte «de la masa precaria explotada» (Noguera, 2019, p. 71). Deriva además de esta posición el imperativo ético y estratégico a tenor del cual no corresponde ya al trabajador de la cultura el adiestramiento de ningún sujeto histórico revolucionario, sino simplemente propiciar, con su acervo y proyección, la autonomía social, en un proceso donde «las experiencias de autoorganización popular» han de representar «la vanguardia», y «la teoría [...] la retaguardia» (Noguera, 2019, p. 115).

El interlocutor preferente del estudio es el jurista o militante de izquierdas, o el lector centrista o conservador interesado en conocer los derroteros teóricos por los que hoy camina la reflexión jurídica crítica. Estamos ante un libro de izquierdas escrito para consumo y provecho de los movimientos sociales de izquierda. Es aquí -creodonde deben encuadrarse sus propósitos principales.

El primero de ellos persigue que se anclen bien los pies en el suelo histórico para poder llegar a plantear alternativas de futuro viables. En este sentido, se revuelve ante todo contra los «proyectos estatólatras» (Noguera, 2019, p. 10), caros todavía a buena parte del progresismo europeo, y lo hace atacando su condición cultural de posibilidad, la que denomina -dando título a la monografía- «ideología de la soberanía», caracterizada por considerar el Estado como el «único núcleo organizador» de la sociedad y el derecho estatal como el único dotado de juridicidad. Además, no califica tal condición como «ideología» arbitrariamente, sino por la convicción de que las premisas jurídico-políticas que comporta suponen una «falsa conciencia» (Noguera, 2019, p. 11), que impide a quienes las movilizan el conocimiento cabal de la realidad sobre la que pretenden operar.

La reflexión del profesor Noguera aspira así a incidir «en la esfera mental de gran parte de las izquierdas» (Noguera, 2019, p. 45) para que en ella se verifique un desplazamiento desde posiciones estatalistas, verticales y monistas a postulados cooperativos, horizontales y pluralistas. Identifica la reluctancia monista ante todo en el garantismo, al que plantea una ambiciosa enmienda, como después se verá. Pero su programa no se identifica tampoco con el derrotismo catastrofista de quienes, 
desde la izquierda, anuncian un inevitable futuro apocalíptico de «sociedades posconstitucionales distópicas» marcadas por "formas de pluralismo Mad Max» (Noguera, 2019, pp. 84, 89). Si al neoconstitucionalismo garantista (al que llama «hiperconstitucionalismo») le señala su desfase histórico, ante la tentación «posconstitucional» de sucumbir al temor generalizado al «colapso» (Noguera, 2019, p. 93) se impone la obligación de «pensar nuevos paradigmas constitucionales capaces de generar dignidad» (Noguera, 2019, p. 99) ${ }^{1}$.

Con este objetivo como irreprochable divisa, el autor se sitúa en el dilema congénito de la izquierda histórica -que tuvo en el arranque de la República de Weimar uno de sus momentos más desgarradores- entre «autoorganización espontánea de las masas» o "extensión de la administración pública enderezada al bienestar colectivo» (Peukert, 2020, p. 43). Y se ubica en esta bipolaridad entre «Estado y autoorganización popular» (Noguera, 2019, p. 130) dejando claro que el propósito práctico de su reflexión teórica es «el fortalecimiento de espacios de autoorganización y autorregulación en el seno de la sociedad» (Noguera, 2019, p. 70) con el fin de lograr formas sólidas de autotutela. En efecto, frente a la creencia usual de las izquierdas de que la sociedad es, de modo preferente, «espacio de mercado y desigualdad», aboga por pasar a concebirla como un posible espacio «de solidaridadigualdad» (Noguera, 2019, p. 44). Así, concluye su obra insistiendo en que la mueve el propósito de empoderar jurídica y políticamente a las colectividades autónomas, contribuyendo con ello a la revigorización de «una nueva racionalidad descentralizadora-comunal» que logre sustituir «parte de lo estatal por la autonomía social». De esta forma se propiciaría la consolidación de «espacios sociales que se autorregulen de manera democrática, igualitaria y con valores opuestos a los del mercado» (Noguera, 2019, p. 146).

Su preferencia no es caprichosa. Obedece a un diagnóstico sobre la tendencia histórica objetiva según el cual el reforzamiento de la sociedad en detrimento de la institucionalidad estatal compone un vector evolutivo insoslayable, algo ya puesto de relieve por otros juristas notables que interesan a nuestro autor (Esteve Pardo, 2013, p. 24). Ante el convencimiento de que los supuestos sociales, económicos e históricos del constitucionalismo social garantista se encuentran agotados, se trataría entonces de intentar redirigir la tendencia mencionada en favor de las clases humildes y las mayorías sociales, rectificando su actual propensión oligárquica y corporativa. Y frente al sálvese quien pueda, o la «resiliencia social salvaje» (Noguera, 2019, p. 96) ${ }^{2}$, como respuestas resignadas a la profunda crisis que atravesamos, invita a apostar por una «resilencia social civil» (Noguera, 2019, p. 97) que implique la organización y coordinación de las colectividades en aras del bien común y como «resistencia» frente al imperio de la competencia descarnada.

Semejante tentativa cuenta con requerimientos estratégicos, administrativos y jurídicos. No se trataría ya, al modo gramsciano, de coagular las «propias formas organizativas» de las "clases populares» para que formen una suerte de «Estado en potencia» (Noguera, 2019, p. 115), presto a desbancar al Estado oficial en el momento del derrumbe causado por sus contradicciones internas. Más bien se aspira a estabilizar una federación de comunas solidarias eliminando del horizonte su conversión estatal. Pero, como se ha insinuado, no por ello se renuncia a todo momento de unidad o de "universalismo» (Noguera, 2019, p. 130), confiando en una

\footnotetext{
1 Con su alusión al «colapso», capta el autor un miedo bien difuso, auténtico rasgo de época, reflejado en series actuales como la homónima de Les Parasites o la muy celebrada de Years \& Years.

2 Debe mencionarse aquí, como antecedente inspirador, a Wolfgang Streek, quien, en su esclarecedora introducción a la versión castellana de How will capitalism end?, señala la "resiliencia» como uno de los principales mecanismos de estabilización individualista del régimen neoliberal en crisis (Streek, 2017, p. 58).
} 
suerte de articulación espontánea entre comunidades igualitarias sin polo central alguno que las coordine y unifique; antes al contrario, se persigue alterar la interrelación ortodoxa entre ambos extremos, el local-popular y el general-estatal, colocando las instancias unificantes al servicio de las iniciativas locales cooperativas. Habría de promoverse así, por ejemplo, «la implementación desde la Administración estatal de políticas destinadas a favorecer, potenciar y proteger la economía social o cooperativa» (Noguera, 2019, p. 70). En sentido paralelo, pero en el ámbito municipal o provincial, habría que incentivar «la activación desde administraciones locales o intermedias de un Derecho constitucional menor de anticipación de experiencias del procomún cooperativo» (Noguera, 2019, p. 129). Y es que, en definitiva, habría que utilizar «el Derecho para facilitar la creación de espacios» de ese "procomún cooperativo», lo cual supone, en primer término, comenzar a reconocer «una nueva juridicidad» a las «experiencias cotidianas» de signo solidario y autonomista (Noguera, 2019, p. 129).

En coherencia con la convicción de que solo mediante la praxis colectiva podrá forjarse una nueva mentalidad jurídica, a cuya cristalización debe acudir el intelectual a posteriori dotándola de forma conceptual, sería este reconocimiento de juridicidad a las formas cooperativas y autónomas de convivencia lo que permitiría «transitar hacia un nuevo paradigma constitucional» (Noguera, 2019, p. 129). Y aquí radica, a mi entender, el tercero de los propósitos de nuestra obra. Persuadido de que las posiciones de izquierda necesitan «construir una teoría jurídico-constitucional propia» en lugar de seguir parasitando la teoría demoliberal (Noguera, 2019, p. 99), esboza en su libro una propuesta de «alterconstitucionalismo» orientada precisamente por la doble necesidad de empoderar a las colectividades y de poner las instituciones y la propia Constitución a su servicio.

En efecto, del libro de Albert Noguera se desprende un replanteamiento pleno del propio concepto de Constitución, que pasa a concebirse como la arquitectura jurídica y procedimental de la autodeterminación colectiva. Sería el soporte jurídicoformal y sustantivo de una suerte de «federalismo horizontal de ciudadanías» (Noguera, 2019, p. 137). Su presencia evitaría que tal consorcio de colectividades cayese en una competencia desordenada y autodestructiva por encargarse de comunicarle «principios de dignidad» universales (Noguera, 2019, p. 137); por eso su propuesta reconoce abiertamente «la necesidad de Constitución», pero «de otra Constitución superadora del paradigma liberal estatista» (Noguera, 2019, pp. 130131), paradigma al que al fin $y$ al cabo sigue atado el garantismo (su «hiperconstitucionalismo») y la izquierda tradicional. $Y$ para trascenderlo, su propuesta toma como premisa la indicación -mezcla de constatación y de señalamiento normativo- de que «la soberanía no radica en la Constitución, sino en las formas de organización de la sociedad» (Noguera, 2019, p. 137).

Con esta apuesta por las colectividades locales autorreguladas en sentido horizontal, antijerárquico y cooperativo o anticompetitivo, el autor -no sé si en un desplazamiento interno- se aleja de las premisas nacional-populares y de los planteamientos constituyentes clásicos para colocarse en escenarios posthegemónicos. Existe ya, a su entender, una contradicción esencial entre la irreductible fisonomía pluralista y fragmentaria de la sociedad y los requerimientos de casi-unanimidad de los procesos constituyentes tradicionales, en los que un determinado grupo social logra con éxito hacer pasar su proyecto parcial de sociedad como anhelo mayoritario, como sentido común de época refrendado de forma amplia y transversal en el acto rupturista de discutir, aprobar y ratificar la Constitución.

La multiplicidad reinante impide enunciar con la eficacia pasada un We, the people constructivo. La fragmentación imperante oblitera, su juicio, la «unificación del 
sujeto» en torno «a una síntesis de identidad única», lo cual, a su vez, bloquea «su configuración en un único centro de soberanía dominante» (Noguera, 2019, p. 136). Indiquemos que en uno de los modelos teóricos que sirve de referencia al autor se encontraba ya la indicación de que, en las sociedades constitutiva y simbólicamente multipolares, «la semántica con la que la sociedad reproduce sentido susceptible de ser conservado» se torna "profundamente insegura», lo que condena a la esterilidad los intentos de resucitar la «confianza en las formas simbólicas estables» (Luhmann y De Giorgi, 1999, p. 104). Añadamos que los momentos históricos de intensa catalización política suelen ser profundamente traumáticos, y por severa que sea la crisis que atravesamos no deja de constituir -al menos hasta el momento- una lenta y triste decadencia que no propicia la sustitución general de la mentalidad jurídica predominante y de las formas ya forjadas de subjetivación política.

Pero lo que de cualquier modo nos interesa apuntar es que, frente a los actos constituyentes como ruptura neta con el pasado, el autor, en sintonía con su intención de trascender la extenuante dicotomía izquierdista entre "reforma» y "revolución», apuesta por un «proceso constituyente ampliado» que obliga a la reconsideración del propio concepto de Constitución. Dejaría de ser el pronunciamiento soberano del poder constituyente del pueblo representado en una asamblea extraordinaria para pasar a concebirse como «institucionalización de una nueva matriz social diferente al Estado moderno» (Noguera, 2019, p. 135). Encontrándose su propuesta de «alterconstitucionalismo» tan solo bosquejada (Noguera, 2019, p. 115), entre otras razones por necesitar para su confección «acabada» de la cristalización de las experiencias cooperativas de que se nutre, no queda al lector meridianamente claro en qué habría de consistir dicha «institucionalización», que yo entiendo al menos en dos sentidos: primeramente, como consagración en el texto constitucional estatal de las conquistas de los movimientos anticapitalistas $y$, en segundo lugar, como reconocimiento del valor constitucional que tienen las plasmaciones normativas de carácter local (su «Derecho constitucional menor») de las formas organizativas solidarias. A su vez, el derecho constitucional podría asumir, en ambos registros (estatal y «menor»), un doble papel: de fomento o incentivo de tales formas de vida cuando resultan aún precarias (a lo que llama «Derecho constitucional de anticipación»), o de consagración de las mismas cuando se encuentran consolidadas (su «Derecho constitucional de consumación»).

\subsection{Aportaciones}

El libro que comentamos cuenta, por tanto, con tres propósitos centrales: operar un cambio en la mentalidad estatalista aún predominante en las izquierdas, promover formas cooperativas de vida y replantear el concepto convencional de Constitución para hacerlo útil a tal objetivo solidario. Aparte de este valor, desenvuelto en el terreno propositivo, con lo adelantado hasta el momento puede además concluirse que uno de los principales méritos de la obra es su vocación teórica. En un tiempo en el que el constitucionalismo como doctrina se dedica principalmente a la exégesis normativa y jurisprudencial, envuelto por lo común en clichés claramente desfasados que lo inhabilitan para comprender el momento histórico presente, Albert Noguera se atreve a replantear las bases teóricas del propio constitucionalismo con el ánimo de inspirar la producción normativa y jurisprudencial, así como la interpretación doctrinal.

Se trata de un gesto, a mi entender, encomiable e intelectualmente estimulante. Como no podía ser de otro modo, pues la producción científica se caracteriza por la acumulación más que por los descubrimientos de nuevos mediterráneos, el replanteamiento teórico-constitucional lanzado por el autor organiza y sistematiza cuestiones ya visitadas por el pensamiento jurídico crítico. Debe en este sentido entroncarse la obra con la rica tradición pluralista y corporativista-democrática 
tanto española como europea. Durante la lectura, es inevitable no traer a las mientes la polémica sobre el pluralismo y la soberanía estatal en la Europa de entreguerras, con las potentes aportaciones de Harold J. Laski y, sobre todo, para los propósitos que nos ocupan, de Georges Gurvitch (Martín, 2017, pp. 223-243 y 284-287). Acude también al recuerdo del lector la dialéctica que se dio en aquel entonces, con la emergencia de las democracias republicanas, entre las formidables fuerzas acumuladas en sociedad y su reconocimiento jurídico con fines de impulso y hegemonización ${ }^{3}$. No cabe tampoco dejar de vincular el tono y fines de la obra con algunas consideraciones de Simone Weil ${ }^{4}$, con las alternativas cooperativas al «Estado providencia» señaladas desde hace tiempo por el propio Rosanvallon (1984), con el pluralismo jurídico atento a las manifestaciones normativas de la vida cotidiana de Santos o con la filosofía crítica del derecho de Óscar Correas. La presente obra debe además enlazarse con aportaciones anteriores del autor en las que se interrogaba acerca de los modos de superar la crisis del Estado social sin incurrir en las trampas habituales del monismo (Noguera, 2012, 2014).

Aparte de su tonalidad propositiva, lo que da el timbre característico al libro que comentamos es, como se ha indicado, su capacidad de construcción conceptual. No solo es que se despliegue principalmente en el terreno de las categorías, lo que convierte la obra en especialmente provechosa desde el punto de vista heurístico; lo singular es su habilidad para pulsar nuestra realidad histórica en transición y traducirla a formas conceptuales útiles al lenguaje jurídico. Tanto sus variados ensayos de «modelización» o «tipificación» de realidades jurídico-políticas complejas como su exposición de las transformaciones económicas y laborales presentes $-v$. gr. las formas de mercantilización del «espacio del procomún colaborativo» (Noguera, 2019, pp. 49, 108)- dan buena muestra de esa facultad para acuñar conceptos que si a veces no son tan sintéticos como sería deseable siempre resultan esclarecedores.

También distingue la aportación del autor el hecho de que esa capacidad de construcción conceptual no obedezca tan solo a fines de conocimiento, sino que se ponga al servicio de la acción política transformadora. Como se ha sugerido, estamos ante un ejemplo transparente de ciencia jurídica partisana, que toma partido de forma explícita ${ }^{5}$. Su objetivo es dotar a las izquierdas de una brújula conceptual más sofisticada y atenida a la realidad presente para que orienten de forma satisfactoria sus luchas emancipadoras. Descifrándola y desvelándola, aspira así a que «las izquierdas» acoplen su «esfera mental» a la particular complexión de la «nueva y compleja realidad» (Noguera, 2019, p. 61), pues solo de ese modo podrán formular «proyectos políticos garantistas» viables y capaces de «garantizar dignidad a las amplias mayorías sociales» (Noguera, 2019, p. 59).

Si lo habitual de las izquierdas mayoritarias ha sido pensar el «campo de lucha por los derechos» de forma «binaria», esto es, como demandas de protección planteadas por los colectivos sociales a un Estado proveedor de prestaciones, la

3 Un ejemplo célebre que suelo citar, y que se halla en plena congruencia con los planteamientos de la obra, fue precisamente el decreto de 4 de julio de 1931 sobre «sociedades cooperativas», poco después convalidado como ley, en el que se trataba de dotar al movimiento cooperativo de los principios, las técnicas y las exenciones fiscales necesarias para que se consolidase y generalizase en sociedad. El legislador republicano era bien consciente tanto de la consistente acumulación de fuerzas que dicho movimiento había logrado durante las décadas pasadas «en ambiente poco favorable» como del hecho de que solo a través de sus cooperativas de producción, venta, mano de obra o crédito podían los trabajadores defenderse eficazmente frente a la competencia capitalista.

4 Entre las líneas definitorias de la reflexión de Weil, destacaba F. Fernández Buey $(2007$, p. 15) «la idea de que la emancipación de los trabajadores será cosa de los trabajadores mismos o no será».

5 En realidad, toda ciencia jurídica toma partido, aun de forma implícita. De hecho, la apariencia de neutralidad técnica en este terreno suele ocultar en vano formas de sesgo descarado. Lo que distingue la obra que comentamos es su franqueza al respecto. 
situación presente exigiría un cambio drástico de estrategia. Caracterizándose «la sociedad actual» por una suerte de «neomedievalismo», esto es, por hallarse dispersada «en múltiples formas fragmentadas de supervivencia y de interés privado» (Noguera, 2019, p. 43), la vía consecuente de intervención en ella obliga a dirigir la mirada transformadora no tanto al Estado como a la propia sociedad. Es aquí, según sabemos, donde el autor encuentra una sólida «alternativa para construir nuevas formas de dignidad»; el requisito para conseguirlo sería generalizar en las izquierdas una nueva mentalidad que impulsase un «proceso de comunitarización generador de solidaridad e igualdad» (Noguera, 2019, p. 45).

Un ejemplo evidente de este significativo desplazamiento lo suministraría precisamente el ámbito del trabajo. Frente a la habitual pretensión de lograr del legislador reformas tuitivas ampliadas para los centros de trabajo tradicionales, una izquierda eficiente debería tomar nota de que el partido se juega hoy en la «tensión entre lo procomún cooperativo y lo procomún corporativo o extractivo» (Noguera, 2019 , p. 46). Así, fenómenos como la uberización de la economía o la propagación de los riders se combatirían con mayores rendimientos si se invirtiesen los esfuerzos, no solo en conseguir nuevas y mejores leyes laborales, sino también en tratar de dirigir el «procomún colaborativo», pues en la disputa por su orientación -si extractivista o solidaria - tendremos «el gran campo de batalla entre capitalismo y sociedad a corto plazo» (Noguera, 2019, p. 46).

A este afán de construcción conceptual con el objetivo de simplificar y hacer comprensible una realidad compleja con vistas a su transformación igualitaria acompaña otro ánimo loable de sentido, digamos, inverso: el que trata de restituir a la fenomenología estudiada toda su complejidad, todos sus ricos y contradictorios matices. Al trazar el escenario sociopolítico en que las izquierdas deben desenvolverse, Noguera rehúye así toda forma de pensamiento unidimensional para optar por representaciones densas, en las que tienen presencia simultánea todos los factores en juego: cítese, por ejemplo, la que caracteriza el espacio sociopolítico por la «simultaneidad» de «Estado, mundialización y fragmentación de tipos de ciudadanía» (Noguera, 2019, pp. 23-24). Esa ampliación del ángulo de visión, con repudio de esquematismos unilaterales, también responde al propósito de describir el «campo de lucha de los derechos» (Noguera, 2019, p. 33) con la máxima fidelidad posible a fin de optimizar las posibilidades de las izquierdas, inspirando con ello «una diversificación de las formas de organización de lo colectivo que, mediante estructuras de organización y prácticas de conflicto distintas, operen simultáneamente» en los diversos «ejes» en torno a los cuales se distribuye el campo citado (Noguera, 2019, p. 113).

Como historiador del derecho, debo destacar el valor especial que tiene la definición del presente histórico como entremezcla saturada de diferentes épocas. Junto a la historia entendida al modo conservador como continuidad tradicional de hilos sustanciales 0 , al modo posmoderno, como estratificación de fases incomunicables entre sí, al menos desde Walter Benjamin comenzó a fraguarse otra concepción más refinada de la historia como acumulación marcada por la simultaneidad, en la que nada de lo acontecido tiene desperdicio. Es la que aquí se pone en práctica. «Una época es siempre un emplaste confuso de varias edades decía el médico y novelista Alfred Döblin-», una amalgama «repleta de residuos de viejos elementos y de fermentos de los nuevos» (cit. en Peukert, 2020, p. 16) Reproduciendo esta visión, para Albert Noguera el «modo de producción social»

6 Benjamin o Döblin llevaban a la filosofía de la historia o la literatura la línea abierta por los «manifiestos futuristas», "cuyo tema debía ser la maquinal vida moderna con su mezcla caótica de acontecimientos simultáneos» bajo la pretensión de que «nada debía presentarse aislado», poniendo énfasis en lo que «se llamaba 'simultaneidad'» (Muschg, 2013, pp. 52-53). 
(Noguera, 2019, p. 13) propio de la actualidad se encontraría signado por la convivencia simultánea de tres marcos espacio-temporales diversos, el «preliberal», el «liberal» y el «posliberal», cada uno de ellos con sus formas singulares de autoridad, juridicidad y legitimidad del poder, así como con su propio «sistema económico». Por eso la «narrativa histórica» también compone un instrumento valioso de lucha por los derechos para la izquierda, pues le permite identificar en el pasado las tradiciones a las que anclarse y las prácticas de acumulación a combatir.

Por último, creo que, en el plano crítico, debe destacarse, por contraintuitiva, su impugnación del garantismo encarnado en la obra de Luigi Ferrajoli. Lo toma el autor como ejemplo paradigmático de discurso jurídico progresista aún atado a «la ideología de la soberanía», en este caso de la «soberanía de la Constitución». Esta dependencia insuperada sería lo que hace que el único «proyecto político de futuro» capaz, en el fondo, de plantear, no signifique otra cosa que «una reconstrucción ampliada del Estado constitucional del siglo XX» (Noguera, 2019, p. 63). Deudor entonces de inercias estatalistas inservibles en un tiempo de prevalencia social, el «hiperconstitucionalismo» resultaría una doctrina mal adaptada a las exigencias de la globalización y del nuevo auge localista. Su necesidad implícita de que los derechos sean amparados por un Estado reforzado, sea nacional o mundial, lo inhabilita parcialmente en una época de crepúsculo estatal. Atrapado en consecuencia en un estrecho positivismo jurídico, para el que los derechos no cuentan con trascendencia normativa a no ser que se encuentren reconocidos expresamente por el ordenamiento, el garantismo se revelaría asimismo incapaz de reconocer la existencia socializada de tales derechos tanto en las formas de vida cooperativa enderezadas a su autotutela como en las formas de lucha por su reconocimiento libradas contra los poderes oficiales.

\section{Flaquezas}

Dejaríamos incompleto este comentario extendido si no reparásemos en las flaquezas que hemos creído detectar en el desarrollo de la argumentación. Téngase de todas formas en cuenta que no alcanzan tales debilidades la condición de aporías, inconsecuencias o errores a rectificar. Puede, de hecho, que no pasen de ser reacciones de perplejidad provocadas por la particular formación del recensor que suscribe estas líneas. Es decir, puede que no pongamos de relieve otra cosa que flaquezas de la lectura más que del texto leído. A efectos de exposición, organizaremos el presente apartado distinguiendo los aspectos metodológicos, de diagnóstico, argumentativos y de aplicación práctica.

\subsection{Metodológicas}

He apreciado al menos dos: una referida a la forma en que se cultiva la historia de las ideas y otra al modo en que se considera empleada la «teoría de los sistemas».

Uno de los flancos del trabajo se desarrolla en el ámbito de la historia del pensamiento jurídico-político. Se reproduce en él la forma de proceder convencional, un tanto apolillada, característica de lo que Adorno censuraba como subjetividad creadora (2004, pp. 35 y 63), es decir, del enfoque individualista que considera la historia de las ideas compuesta por tradiciones, forjadas a su vez por autores singulares que, influidos por antecedentes y precursores, crean sistemas nuevos y originales plasmados en obras concretas en forma, habitualmente, de grandes y célebres libros. Se trata, desde luego, de una opción metodológica respetable, 
aunque pueda afinarse mejor la reconstrucción de ciertas tradiciones ${ }^{7}$. Pero es una opción precrítica, y no deja de ser motivo de perplejidad el que a estas alturas no se practique teniendo presente la impugnación que la historia ideológica distribuida en torno a las unidades de «autor» y "obra» obtuvo, tiempo ha, del análisis genealógico de los discursos (Foucault, 1997, 2002). Además, en el caso concreto que nos ocupa, la opción puntual por esta narrativa historiográfica resulta inesperada por poner énfasis el autor, para cuestiones de presente, en el plano más acertado de la «mentalidad» y los «paradigmas».

Pero resulta aún más llamativa esa elección ocasional por tratarse de un autor abiertamente materialista. En efecto, no solo se opta por contar las ideas como excogitación de autores singulares, sino que a veces se atribuyen a tales ideas facultades taumatúrgicas de transfiguración de la realidad social que, en mi opinión, escapan a su alcance. Así, por ejemplo, se afirma que «la separación entre sociedad y Estado empieza a diseñarse» con una obra célebre de Adam Ferguson (Noguera, 2019, p. 34), o que fue Adam Smith «quien lleva a cabo» la «sustitución de lo político por lo económico en la explicación de la institución de lo social» (Noguera, 2019, p. 35). En sentido similar, se sostiene que la generalización de unas ideas (las de «la soberanía natural directa» y la de «los individuos como entes autónomos titulares de derechos individuales absolutos») permite que se produzca el formidable efecto material de la «descomunalización de la sociedad» y la «aniquilación de los viejos actores sociales» (Noguera, 2019, p. 17).

A mi juicio, no hay proceso de transformación operada en la estructura de las relaciones sociales que no coimplique, en diversa proporción y de forma inextricable, factores culturales y materiales. En los intervalos de cambio suele presenciarse la generalización ascendente de una cosmovisión cultural que logra ir desplazando de la escena a la concepción anteriormente predominante, pero también una concatenación de factores en el plano de las relaciones socioeconómicas que propicia -que convierte en plausible y aceptable- dicha hegemonización cultural paulatina. Se podría objetar que se trata de una simple forma de hablar o de narrar la materia expuesta, recurriendo a la metáfora o ficción de que los autores crean ideas que a su vez generan una nueva sociedad -o una nueva concepción acerca de la misma- para aludir a procesos complejos de cambio. Pero se aceptará que justo esa narrativa entra en tensión con los postulados de una obra que, para el tiempo presente, considera la teoría y al intelectual como retaguardia al servicio de la praxis emancipatoria. Y se consentirá también concluir que con esos recursos metafóricos - propios de la filosofía del «como si»- nos exoneramos de la enojosa tarea de esclarecer fenómenos alambicados, como el de que el capitalismo se caracterice en esencia por la disolución de las formas tradicionales de vida (Deleuze, 2017, pp. 21-22).

Por último, no parece del todo acertado recurrir a una teoría de tan formidable densidad como la sistémica para fundamentar la mera sugerencia de la "superposición de sistemas de organización social de distintas épocas históricas» (Noguera, 2019, p. 25). No solo hay cierta incongruencia entre la exposición de la modernidad como diferenciación de esferas realizada por la teoría de los sistemas (Luhmann, 1998) y la simultaneidad de escenarios históricos apuntada por Noguera. Es que tampoco sirve la opción teórica de Luhmann para avalar una concepción de «sistema» social en la que se desagregan, al esquemático modo marxista, las

7 Es dudoso, por ejemplo, que el «fundamento» del «cristianismo social» se encuentre «en el Codice sociale de Malines de 1937», como dice (Noguera, 2019, p. 38), y no, por ejemplo, en la encíclica Rerum novarum de Leon XIII. También es dudoso, como después se indicará, que la idea de atribución indirecta de la soberanía desde el pueblo al monarca, en lugar de entenderla concedida directamente por Dios, sea patrimonio de la modernidad. 
estructuras económicas y las «superestructuras jurídico-políticas» (Noguera, 2019, p. 25).

\subsection{De diagnóstico}

Nada cabe objetar a la crítica del Estado como forma suprema de organización del poder y la sociedad, ni a la censura teórica al monismo jurídico. Y poco puede reprocharse a la doble y simultánea tendencia que el autor señala hacia la «homogeneización global» y la «fragmentación» local (Noguera, 2019, p. 22), que erosiona el estatalismo y que está incorporada como constatación a la cultura del jurista al menos desde los años 1990 (Castells, 2000). De hecho, diríase que el nudo problemático teóricamente relevante a estas alturas ha de residir en la cronicidad de esta crisis del Estado, hecho jirones desde arriba y por abajo pero misteriosamente en pie.

Más reticencias provoca que de tales comprobaciones se derive una suerte de filosofía de la historia. Cuando se afirma «la inevitabilidad de un cada vez mayor repliegue garantista neoliberal» (Noguera, 2019, p. 47), ¿no se entienden en cierto modo los procesos históricos como marcados por la fatalidad? Podemos estar conformes en que, con los elementos en juego, la distribución de fuerzas en presencia y las potencialidades y regularidades a la vista, se formulen pronósticos de futuro, pero ¿no suelen responder también los acontecimientos históricos a factores sorpresivos, azares disruptivos o emergencias inesperadas? ¿No está marcado el decurso histórico por cierta aleatoriedad impredecible que imposibilita la atribución de «inevitabilidad» a ninguna desembocadura?

De hecho, el comentario presente cuenta con la ventaja relativa de haberse escrito durante la rotunda emergencia sanitaria que supone la pandemia que padecemos. Y parece que la respuesta institucional a la misma en Europa ha vuelto a colocar sobre el tapete una centralidad estatal -centralidad, además, de carácter "centralista», valga la redundancia- que al menos erosiona la solidez de ciertos pronósticos de disolución de la estatalidad en lo social. Es más, cuando el Estado ha jugado a la abstención para afrontar el problema, los resultados han empeorado considerablemente. No quiere esto decir que en un futuro inmediato no pueda revelarse que el mejor modo de responder a la crisis sanitaria sea la autoorganización de las fuerzas sociales, pues bien cabe que ante el injustificable inmovilismo de las administraciones -en materia educativa, por ejemplo- sean los propios núcleos sociales -o familiares- los que se coordinen para satisfacer los fines desatendidos. Solo se quiere apuntar la dimensión de impredicibilidad de los procesos históricos, que torna problemáticos algunos diagnósticos del autor. Es una evidencia que se incorpora al apuntarse con prudencia que «la transición hacia nuevas formas de alterconstitucionalismo puede durar todo el siglo XXI» (Noguera, 2019, p. 115), pero no por ello se renuncia a considerar tácitamente la historia como sobredeterminada por vectores de fuerza marcados por la fatalidad.

Su intención, desde luego, es encomiable. Convencido de que la inercia de los acontecimientos nos conduce al imperio de la sociedad en el ámbito tanto global como local, es consecuente al señalarnos que el mejor modo de intervenir en la realidad en términos de igualdad y emancipación consiste en sumarse a ese proceso de socialización para reorientarlo hacia coordenadas de dignidad. Pero téngase en cuenta que validando como ineluctable esa dirección de la historia, hasta el momento sumamente provechosa para las posiciones neoliberales, se corre el riesgo de reforzar tales posiciones y de desactivar o neutralizar ciertos contrapoderes tradicionales. Así, por ejemplo, si entendemos que en el futuro se van a generalizar las fórmulas de «autorregulación declarativa» (Esteve Pardo, 2013), lo cual nos obliga 
a servirnos de ellas también desde posiciones progresistas, procedemos a una validación de resortes y mecanismos de dominación privados, dándolos por inexorables, en lugar de centrarnos en revelar todo lo que contienen de heteronomía disfrazada de autonomía (Rügemer, 2013). De hecho, si tenemos presente las advertencias de Karl Polanyi (2003) sobre los límites objetivos intraspasables por la pan-mercantilización de la sociedad, podríamos deducir, en sentido justamente inverso, que dichos mecanismos autorregulatorios de apariencia flexible constituyen fenómenos disfuncionales condenados al fracaso (o a la compensación institucional) por generar demasiadas dosis de desorden, inequidad y sometimiento.

Dar por buena la tendencia a la socialización infrainstitucionalizada con el fin de liderarla y redirigirla puede representar una forma de reforzarla en beneficio de las fuerzas que, por su mayor capacidad técnica y organizativa, la han impulsado y se han aprovechado preferentemente de ella. Algo similar acontece cuando se considera sin más extinguido el mundo que daba soporte a la razonable garantía de los derechos sociales. Diríase que el autor considera un ejercicio de realismo pensar que los supuestos económicos e institucionales para la garantía universal de derechos como la sanidad, la educación, el desempleo o las pensiones se encuentran ya históricamente agotados. Por eso la izquierda debería cambiar de fase y pasar a una posición en que se abogue de forma prevalente por fórmulas cooperativas y horizontales de autotutela. ¿No implica este salto ningún riesgo de vaciar el agua sucia con el niño dentro, con un niño además bastante crecidito? ¿No refuerza las posiciones neoliberales que pretenden liquidar los sistemas públicos de educación, sanidad y pensiones aún en pie? ¿O es que en un país como España no tienen las mayorías sociales la educación primaria y secundaria garantizada, o la asistencia sanitaria asegurada? ¿No tienen las capas trabajadoras asegurada también la integridad de su renta mientras se padece enfermedad, o garantizado el ingreso a un modesto pero existente sistema público de pensiones? ¿Puede tomarse como constatación de la realidad un probable escenario futuro mejor que un modelo estatal vigente en el que aún se cuenta con un acceso general a dichos servicios y prestaciones? ¿La mejor forma de frenar su deterioro y revigorizarlos es darlos ya por finiquitados, defendiendo su trasvase pleno a una organización comunal sin empaque alguno a día de hoy? ¿Resultará aceptable para las mayorías sociales a las que se quiere interpelar la invitación a que procedan estratégicamente según la ficción de que, a la vuelta de la esquina, ninguna de las garantías presentes va a existir, por lo que es mejor autoorganizarse en comunas en lugar de defender las conquistas institucionales pasadas? ¿No se aprecian ciertos peligros tácticos en fundamentar la acción colectiva en la predicción de que la tutela estatal de los derechos está, por necesidad, liquidada, con independencia de los cambios que puedan darse en la correlación de fuerzas y en las estructuras burocráticas?

\subsection{Argumentativas}

Si sus diagnósticos parten de una filosofía implícita de la historia que puede resultar discutible, algunos de sus argumentos se apoyan en ciertas presunciones tácitas (o en determinadas ambigüedades) de las que también puede disentirse.

Veámoslo en su crítica al garantismo. Para fundamentarla, el autor se ve obligado a recurrir a la filosofía de la historia mencionada. Piensa que una de sus tachas principales es el conformar una «propuesta teórica construida en sentido inverso al que va la realidad práctica», pues, requiriendo para su realización "un fortalecimiento del Estado» contradice «la tendencia abierta e irreversible de nuestras sociedades» al debilitamiento del mismo (Noguera, 2019, p. 68). Seguidamente valoraremos cuánto de estatalista puede tener una doctrina cosmopolita (Ferrajoli, 2018); interesa ahora insistir en la imprecisión analítica de toda forma de 
determinismo, en la citada impugnación que al ocaso del Estado han hecho los actuales momentos de emergencia y en la tensión interna que para la obra supone una refutación de este género.

En efecto, por más metáforas filosófico-históricas que recubran nuestro entendimiento, no existen tendencias unilaterales irreversibles en los procesos sociales. Claro es que la historia no se puede desandar para regresar de forma limpia a momentos pasados idealizados. Todo escenario futuro es, por esencia, nuevo, pero en él pueden hallar mayor o menor realce aspectos pasados ya cancelados, pero significativamente recobrados, como la propia idea de simultaneidad de marcos espacio-temporales aplicada por el autor sugiere. Pongamos un ejemplo sencillo: la «gran regresión» desencadenada en 2008-2010 no nos devolvió al siglo XIX, claro, pero factores como la individualización de las relaciones laborales rimaban intensamente con rasgos salientes del sistema decimonónico. Trasladados a nuestro terreno, diríase que abundan los indicios (económicos, productivos, comunicativos) que señalan un recrudecimiento de la globalización, con las consiguientes contestaciones locales. Pero no puede olvidarse que cada peldaño recorrido en el proceso globalizador en el terreno institucional ha sido decidido por los Estados, y nada impide que, ante la presión de las circunstancias, ese camino pueda desandarse, no para regresar a los Treinta Gloriosos, sino para abrir un nuevo escenario de predominio estatal. De hecho, las últimas contiendas electorales en Europa y América tienen como eje divisor el de la soberanía estatal-nacional frente a las formas de socialización mundializadas; está así por ver que el futuro inmediato no halle en el refuerzo del Estado una contestación compensatoria a las contradicciones de la globalización capitalista. ¿No habría que aprestarse también a saber liderar esta posible reversión? Y con ello no quiere desmentirse el pronóstico de otoño estatal sino recordar simplemente que, encontrándose abierto el desenlace, no sirven del todo las previsiones de futuro para impugnar doctrinas bien trabadas.

Si la excepción demuestra lo decisivo, diríase además que las actuales circunstancias, con su respuesta preferentemente cristalizada en los Estados, nos persuaden para poner en cuarentena el anuncio de su retirada.

Por último, conviene resaltar hasta qué punto puede que el autor, con su inclinación determinista, esté faltando a sus propias consideraciones estratégicas. Buena parte de su obra se encarga de trazar el complejo y polifacético marco en el que se luchará por los derechos. Ese escenario se caracteriza -ya se ha dicho- por la simultaneidad de rasgos contradictorios entre sí, lo cual impone la obligación de operar en cada uno de sus puntos cardinales, sin descuidar ninguno, si se pretende desplegar una acción colectiva eficaz. Pues bien, de tales premisas podría deducirse una crítica al garantismo que le señale que, atendiendo a los polos de la mundialización y del Estado, descuida el de las formas autónomas de vida social, pero no una pretendida impugnación que le acuse de un décalage insubsanable por atender a extremos que el propio autor considera marcos insorteables de la acción política actual. Si la saturación histórica presente nos impele a actuar también en un universo estatalista de signo liberal, si el espacio político se define asimismo por sus polos estatal-mundial, no cabe desperdiciar sin más una doctrina progresista y emancipadora sumamente elaborada justo en esos registros por no poner sus pies en la realidad.

Pero es que puede que tampoco sea del todo acertada la reprobación que ve en ella una teoría demasiado deudora de «la lógica de la ideología de la soberanía» -aquella, como sabemos, «en la que el Estado se conforma como único centro de poder organizador de la sociedad, y el Derecho conectado en exclusiva a él (la 
Constitución) se convierte en forma de regulación omniabarcante» (Noguera, 2019, p. 68)-.

No puedo dejar de manifestar la extrañeza ante semejante caracterización del garantismo, pues, a mi entender, un poder funcionalizado enteramente por los derechos, con las limitaciones y los imperativos que ello supone, es decir, con la exclusión casi completa de la potestad autónoma de decisión que esto implica, no instituye nada parecido a un Estado soberano. De hecho, resulta revelador que su principal exponente se ocupase monográficamente de dar por liquidada la doctrina de la soberanía estatal como forma correcta de comprensión del derecho en las democracias constitucionales y en la actual sociedad internacional (Ferrajoli, 1995). Y tampoco creo que resuelva mucho el contestar que la soberanía radica entonces, según el garantismo, en la Constitución, pues nos estaríamos refiriendo a una simple metáfora que designa precisamente lo contrario, su ausencia. Es decir, con semejante expresión no se querría significar sino que son los individuos y colectivos los que, en el ejercicio o disfrute imperturbado y garantizado de sus derechos constitucionales, acometen la producción y reproducción de la sociedad. En tal sentido, el garantismo compone, en mi opinión, más una doctrina "sociocéntrica» que "estatólatra», pues en ella los poderes públicos, en su función de garantía e igualación, se hallan al servicio del ejercicio individual y colectivo de los derechos operado en sociedad como forma principal de su actualización. No existe en ella, por tanto, «subsunción de la sociedad en el Estado» (Noguera, 2019, p. 69) sino más bien disolución de la institucionalidad estatal o internacional en la trama social, a cuya reproducción autónoma sirve.

Otra cosa es que lo que el autor denomina «hiperconstitucionalismo» considere que los derechos solo se pueden encontrar razonablemente garantizados si se da «la intermediación "racional" del Estado», a la que habría que añadir ahora también la intermediación igualmente racional de las instituciones internacionales, debidamente constitucionalizadas, si queremos ser fieles a las sugerencias propositivas de Ferrajoli. Puede pensarse, desde luego, que los derechos resultan más eficazmente protegidos mediante fórmulas cooperativas de autotutela que a través de la intervención estatal (o público-internacional). No es el caso de quien suscribe, como seguidamente se dirá. Pero lo que a mi juicio supone un salto argumental discutible es deducir de esa atribución preferente de funciones de garantía al Estado una suerte de inclinación monista, a tenor de la cual sería la instancia estatal «el único poder organizador de la sociedad», pues más bien la ordenación social procedería de la autodeterminación individual y colectiva institucionalmente asegurada.

Por eso, en este punto, la principal debilidad argumental acaso resida en la propia descripción de la «ideología de la soberanía». Es posible que sean muy pocos los que la secunden en los tonos severos con que el autor la caracteriza. Y es que puede creerse -incluso desde una perspectiva crítica (Bourdieu, 2014)- que el Estado continúa siendo a día de hoy una instancia formidable de universalización o generalización, pues los particularismos que quedan sancionados en sus leyes y aparatos administrativos alcanzan un grado incomparable de obligatoriedad para el conjunto de la población, sin que ello suponga desconocer dos evidencias elementales, señaladas para la ciencia jurídica desde los tiempos de Georg Jellinek o Hermann Heller: la existencia de múltiples núcleos de poder social y económico, que pugnan por la ratificación de sus pretensiones por la ley estatal, y la fuerza aglutinante y normativa de los hechos alentados o secundados por tales núcleos. Así, puede sostenerse que el Estado sigue constituyendo hoy el principal foco generalizador de normas y conductas sin por eso creer en absoluto que constituye el «único núcleo organizador de la sociedad desde el que irradia el poder» (Noguera, 
2019 , p. 21). Es más, cabe seguir adjudicándole esa virtualidad generalizadora y pensar al mismo tiempo que se encuentra más debilitado que en el último siglo, por estar a merced como nunca de centros decisorios extraestatales con la pérdida consiguiente de su autonomía como actor político.

Creo que la inercia mental a combatir por el pensamiento crítico habría quedado mejor caracterizada como monismo que como soberanismo. Al fin y al cabo, el entero mapa conceptual que el autor delinea para uso y provecho de los movimientos sociales de izquierda previene, ante todo, frente a toda forma de raciocinio o análisis unidimensional. Obliga a tener presente todos los ángulos y estratos del espacio político para optimizar su lucha. Eso le lleva, como sabemos, no solo a no renunciar, sino a incorporar a su propuesta un necesario polo generalizador y universalizador. Y reconoce, en un gesto sincero que le aproxima al garantismo, que a día de hoy no es sino «la Constitución» el «principal instrumento democrático de universalismo» (Noguera, 2019, p. 130). La «Biblia de los ateos», como la llamase el periodista Jesús Quintero, sigue siendo para el autor un punto de referencia inexclusable del "alterconstitucionalismo» que promueve. Por eso, si cabe plantear alguna objeción fundada a la obra que comentamos, es que, faltando a la obligación de la interrelación o dialéctica permanente que su aportación conceptual impone, incurra ella misma en una forma relativa de monismo o unidimensionalidad. Debiendo la teoría y la praxis de izquierda atenerse a un trilátero complejo, donde comparecen por igual la institucionalidad internacional, la estatal-constitucional y la fragmentaria de los núcleos sociales privados, diríase que buena parte de su aportación, incluida su visión de la Constitución ${ }^{8}$, acusa un sesgo bien ostensible en favor de las formas cooperativas de vida y en detrimento de la estatalidad. Es más: como el propio autor indica, él mismo terminaría por recaer en el resabio soberanista, al localizar preferentemente la "soberanía» (recuérdese, como instancia de producción de lo social y de aprobación del derecho válido) en las comunidades solidarias (Noguera, 2019 , p. 137), cuando habría sido mucho más correcto hablar, en este caso particular -como él mismo hace en otras ocasiones-, al modo de Castoriadis o Ranciére, de «autonomía social».

Ya sabemos -y cerramos así, circularmente, el apartado- que este sesgo procede de un diagnóstico sobre el curso histórico que consideramos problemático. Añádase ahora que a ese diagnóstico se le suma también un plusvalor no menos discutible concedido a todo lo que proceda de «los sectores populares y los movimientos sociales» (Noguera, 2019, p. 11). Seña de identidad de la izquierda intelectual, la ecuación de lo «popular» y lo emancipador juega en el terreno del lenguaje la función emocional de identificar la fuente del bien, el sujeto colectivo del que por necesidad habrá de proceder una racionalización democrática e igualadora esto es, justa- de las relaciones sociales. Pero obsérvese que esa apelación emotiva a lo «popular», o a los «movimientos sociales», pocas veces suele venir acompañada de los estudios sociológicos empíricos que permitan localizar en las capas populares tales bondades. Tampoco de los análisis conceptuales que delimiten a qué nos referimos cuando hablamos de «pueblo». Y resulta que los análisis disponibles, o nos hablan de su precaria existencia actual, en tensión permanente con las pretensiones oficiales de fundar "una sociedad exclusivamente de clase media» (Todd, 2018, p. 431), o bien nos revelan una poderosa funcionalización objetiva de tales estratos por parte de los poderes socio-económicos, muy visible en la abstención generalizada de

8 Aprovéchese para apuntar las interferencias que genera en un discurso jurídico progresista utilizar una fuente netamente franquista como Luis Sánchez Agesta para sustentar de algún modo su visión universalista de Constitución (Noguera, 2019, p. 131). 
las capas más desfavorecidas en los comicios o en sus mismos hábitos televisivos y alimenticios.

Por eso la apelación confiada a lo popular puede desempeñar una función en los discursos de izquierda similar a la que desempeña la fe en una propuesta católica. Solo este plusvalor tácito, con los deseos voluntaristas que alimenta, puede dotar de base argumental implícita a pronósticos como el que se lanza sobre los sectores excluidos y vulnerables: "Para muchos de estos grupos sociales, la autogestión comunitaria empieza a operar y operará cada vez más como una vía alternativa de acceso a la ciudadanía por canales distintos a los estatales, de los que están excluidos, y por tanto como vía de inclusión en la sociedad» (Noguera, 2019, p. 23). Una somera ojeada a la situación circundante sugiere que otros escenarios son también posibles. No resulta así disparatado pensar que tales sectores, en su pugna por un reconocimiento estatal tradicional, puedan ser fuente de refortalecimiento del Estado, y no por necesidad de signo democratizador, sino autoritario. La historia nos suministra además ejemplos de revigorización dictatorial del Estado alimentada por las capas populares, de «amplias masas [volviéndose] nacionalistas en medio de la depauperación» (Reich, 2020, p. 78), hasta el punto de que «ya en el año treinta [en Alemania], una gran parte de la clase trabajadora dio sus votos a los nacionalsocialistas» (Weiss, 2003, p. 169).

\subsection{Aplicativas}

Situar una de las flaquezas de la argumentación del libro en su sesgo favorable a las formas comunitarias de vida nos conduce, por último, a las dificultades de aplicación de su propuesta. Compartimos su inclinación por subrayar la «importancia del procomún colaborativo» para "las clases populares» a fin de guarecerse frente al «desmantelamiento de lo público y la mercantilización de la sociedad», pero diríase que iniciativas y fenómenos como los "grupos de comaternidad y crianza», las "cooperativas de vivienda» y "consumo» o los «bancos de tiempo» (Noguera, 2019, p. 46) carecen a día de hoy de incidencia estructurante alguna. El propio autor lo reconoce al afirmar que «no existe en nuestras sociedades, fuertemente individualizadas y contractualizadas, esta red articulada y consolidada de formas organizativas de lo colectivo» (Noguera, 2019, p. 116). «Ello nos obliga a construirlas», deduce de tal carencia. ¿No supone esto otra forma de situar a las izquierdas en contra de la tendencia histórica predominante, con las consecuencias de irrealismo que ello comporta? En cualquier caso resulta un convencimiento que confiere un tono propositivo predominante a una obra que en principio parecía distinguirse por no despegar los pies en ningún momento del suelo.

En efecto, el propósito que gobierna el trabajo, como ya se sabe, es reorientar la acción institucional y las políticas públicas hacia el empoderamiento de las comunidades. Pero con ello se produce una confirmación indirecta de lo que al parecer era objeto de desmentido general, esto es, que el Estado sea el organizador social por excelencia, dato reflejado aquí en el hecho reconocido de que sin el auxilio institucional de las administraciones públicas (del Estado) poco recorrido independiente puede tener el tejido cooperativo. A esta relativa incongruencia debe añadirse que, probablemente, ni siquiera de ese modo se lograría una eficaz protección de los derechos individuales y sociales. Las comunidades locales solidarias, aun dotados de juridicidad sus cánones de conducta y amparados por un derecho constitucional de nuevo cuño, carecerían de los medios técnicos, financieros, institucionales y personales necesarios para satisfacer fines vitales generales. Que se constate que a día de hoy buena parte de tales recursos están en manos de la 
«sociedad», y no del Estado, no debe engañarnos acerca de la evidencia de que aquí, con sociedad, se quiere decir «capital», y que solo el Estado y los organismos internacionales componen a día de hoy, al menos en potencia, un contrapeso proporcional a esa acaparación privada de recursos. Vaciarlos aún más en nombre del empoderamiento de un tejido cooperativo por construir puede constituir una estrategia contraproducente condenada a reforzar al adversario.

Bien está recordar, a la manera de Poulantzas, que conquistar ciertas posiciones en el gobierno no implica en absoluto controlar el Estado para poder llevar a cabo su reorientación en favor de los derechos sociales. Demasiadas inercias autoritarias y regresivas están incrustadas en sus aparatos como para creer que la transformación de la sociedad es mera cuestión de victorias electorales relativas y legislación formal progresista. Estamos de acuerdo en eso. Pero con idénticas dificultades nos tropezaremos si la alternativa consiste en que «la izquierda transformadora» conquiste el gobierno, o la mayoría parlamentaria, a fin de redirigir el esfuerzo de las administraciones a favor de las formas cooperativas de vida (Noguera, 2019, p. 127). Es más, acaso las dificultades se redoblen aquí, toda vez que la trama colectiva solidaria a la que se confía la emancipación está por construir, mientras que la trama estatal garantista está deteriorada pero en pie. Y la ocupación de determinados vértices del Estado resultaría en todo caso obligatoria, pues desde los tiempos de la "Comuna de París» conocemos el «poder creador de las masas obreras en movimiento», pero también «la incapacidad radical de un movimiento espontáneo cuando se trata de luchar contra una fuerza de represión organizada» (Weil, 1933, p. 81).

Incluso aceptando que la acción institucional del Estado se dirija con preferencia a tales fines de refuerzo cooperativo, puede que al final volvamos a encontrarnos con la necesidad de que dicha intervención sea la generalizadora y universalizadora que parece despreciarse como «soberana». Me explico. Por aquella fe en lo popular recién aludida, es usual en las izquierdas pensar las colectividades locales infraestatales al modo romántico como comunas igualitarias en las que se vive en libertad. Se piensa en este sentido, de forma automatizada, que lo que proceda de las «consultas populares vinculantes», de los «vetos populares» o de los «consejos de participación» será, por necesidad, fuente de bondad y emancipación, base para la autodeterminación colectiva (Noguera, 2019, p. 139). No se discute que el hábito participativo que estos dispositivos ayudan a sembrar sea, en sí mismo, positivo, sino la presunción de que las manifestaciones de voluntad popular no puedan estar poderosamente mediadas por las pulsiones del poder social.

La experiencia práctica nos revela, por el contrario, que la reducción de la escala del espacio político, donde los elementos de la racionalidad abstracta burocrática ceden en favor de criterios individualizados de equidad, es directamente proporcional al blindaje de cacicazgos y a la institución de redes clientelares. Por eso la afirmación de la soberanía de las comunidades, si no se quiere traducir en el imperio incontrastado de las jerarquías privadas internas a cada comuna, debe verse acompañada por un momento igualador y universalista tangible, que, como el autor reconoce, sigue siendo la Constitución, pero aparejada al Estado que la despliega y realiza y entendida como instancia de reconocimiento de una ciudadanía republicana igualitaria (y no de múltiples ciudadanías heterogéneas). 


\section{Historia sobrante}

Una parte no menor de los diagnósticos y pareceres del autor se fundamenta en representaciones historiográficas. Estamos ante una obra de derecho constitucional atenta asimismo a la historia constitucional. $Y$ conviene al respecto reconocer de entrada que esa atención por el pasado se plasma en consideraciones mucho más atinadas que la doxa de uso corriente entre constitucionalistas. Sin embargo, la narración historiográfica que el autor despliega no responde a fines de investigación sino de fundamentación argumental, lo que invita a preguntarse si este modo de razonar jurídicamente es imprescindible, sobre todo cuando se ve obligado a operar ciertas distorsiones en la reconstrucción del pasado a fin de depurar las funciones actuales de lo que llama «narrativa histórica».

\section{1. Época clásica}

Que el pluralismo jurídico y político es el signo que distingue la civilización anterior al ciclo revolucionario del siglo XVIII es aserto todavía pendiente de generalizarse en la historiografía. Mucho más en las representaciones historiográficas movilizadas por la ciencia del derecho, aún prendida -cuando trata de explicar el periodo que va del Renacimiento a la llustración- a categorías confusas como las de «Estado-nación» o «absolutismo». No es en principio lastre que ralentice a nuestro autor. Antes al contrario: una doctrina como la de Bodin, invocada por la perspectiva convencional como génesis del absolutismo monárquico, resulta aquí empleada con la correcta precaución de señalar que se desarrolló «sin modificar la estructura de la sociedad medieval» (Noguera, 2019, p. 13). La soberanía moderna no canceló el pluralismo jurídico; más bien lo tomó como base social sobre la cual actuar. Se tiene entonces claro que, a través del "contractualismo» y la «secularización», solo "a finales del siglo XVIII la soberanía se constituirá en modo de organización social» (Noguera, 2019, p. 14).

Y, sin embargo, el paradigma opuesto, e incompatible, no deja de aparecer, haciéndonos incurrir en una aporía sobrante. No solo se trata de que se sigan empleando referentes bibliográficos bien desfasados al respecto (Noguera, 2019, p. 21, con alusión a J. A. Maravall), ni de que se verbalicen categorías incongruentes cuando se habla del "orden de Estados-nación westfalianos», como si de la paz de Westfalia saliese otra cosa diferente que las monarquías pluralistas, compuestas, patrimoniales y dinasticistas tradicionales (Teshke, 2011). La cuestión es que no cabe constatar un pluralismo político irreductible para la que Foucault llamaba «época clásica» y al mismo tiempo sostener que «la aparición, a partir del siglo XVI, del Estado-nación moderno implicó el paso de un modelo descentralizado a un modelo centralizado de poder y Derecho», con «un territorio claramente delimitado», «las instituciones comunitarias y corporativas intermedias de la sociedad medieval» prácticamente liquidadas y con «un nuevo sujeto de referencia: el individuo» (Noguera, 2019, p. 34). Como el propio autor sugiere en otros pasajes, nada de eso acontece y empieza a generalizarse en la Europa continental al menos hasta finales del siglo XVIII.

Semejante aporía nos coloca en el umbral del desacierto historiográfico, en el que quizá nos adentramos cuando se afirma que entre los siglos XVII y XVIII se dio un cambio en la «forma de acceso de la autoridad a la soberanía», pasándose de una concepción «directa», como asignación divina, a otra «indirecta», como suerte de delegación popular. Se desconoce con ello que un rasgo saliente del pensamiento escolástico medieval, también visible en su reformulación altomoderna, fue el discutir que «la vía de acceso del monarca a la soberanía» fuese "por atribución directa de Dios» (Noguera, 2019, p. 15). En efecto, la idea de que «la soberanía no es algo 
entregado directamente por Dios al monarca» (Noguera, 2019, p. 15) no es indicio de modernidad, pues ya está muy presente en los discursos jurídicos medievales de base romanista, siempre atentos a la limitación objetiva de las potestades del monarca en beneficio del resto de actores políticos y sociales (Hespanha, 1982, p. 302; Agüero, 2006). Cabe incluso que en el antiguo régimen no nos encontremos con una atenuación, sino con un recrudecimiento de la doctrina del «derecho divino» de los reyes: así, mientras la expresión Dei gratia referida al poder regio podía designar en el universo medieval la sujeción del monarca a límites trascendentes, ya en edad moderna comienza a significar que responde solo ante la divinidad. Podría objetarse, con todo, que las concepciones medievales «indirectas» elevaban a la condición de titular directo del poder a un populus jeráquicamente integrado, y no tanto a los «individuos» como «titulares de derechos naturales absolutos» (Noguera, 2019, p. 16), radicando en este individualismo el timbre de la modernidad; $y$, sin embargo, resulta que tampoco era extraña al pensamiento jurídico medieval y teocéntrico, no solo la concepción de unos derechos colectivos positivados en cartas y fueros concretos (Hespanha, 1982, p. 315), sino también la idea de unos iura naturalia de raíz divina y atribución personal que el monarca no podía arbitrariamente atropellar (Tuck, 1981; Vallejo, 2012, p. 161).

Pero, por lo general, aparece correctamente representada a nuestro juicio la época «preliberal» como marcada por el comunitarismo y los criterios materiales de equidad. Otra cosa, en línea paralela a lo ya sostenido, es que, como se dirá al final, esa representación deba ser hasta cierto punto manipulada para que responda a la función política de avalar, en la historia, el corporativismo democrático que se anhela.

\section{2. Época moderna}

Más certera me resulta la representación que el autor, en apoyo de sus argumentaciones, realiza sobre la época liberal desde el punto de vista del derecho y el ejercicio del poder. Introduce algunas referencias constructivas sobre la revolución inglesa que considero de valor (Noguera, 2019, p. 121). Concuerdo con su visión de cómo una arquitectura institucional orientada, en principio, a la liberación de los individuos respecto de las ataduras tradicionales, constituyó, al final, un dispositivo bien trabado de dominación clasista. Sin embargo, por la utilidad que pudieran encerrar, no me resisto a lanzar algunas consideraciones críticas. Quizá todas ellas se reconduzcan a la insuficiencia derivada del exceso de abstracción -o «modelización»- al caracterizar la época liberal, sin distinguir en ella dimensiones internas cualitativamente diversas.

Así, en la fase de antecedentes, resulta discutible el hecho de que, con antelación a la revolución, no existiese «en Francia un movimiento progresivo relevante que permitiera el tránsito del feudalismo al capitalismo» (Noguera, 2019, p. 117). Los fisiócratas y sus proyectos utilitaristas desempeñaron, por el contrario, una función económica de signo liberal-individualista muy presente en las primeras reformas revolucionarias (Mannori y Sordi, 2001, pp. 182 ss.).

Además, buena parte de las aseveraciones realizadas por el profesor Noguera sobre la fisonomía jurídica del marco histórico «liberal» se adecuan, en realidad, al acto de ruptura revolucionaria $o$, en otras ocasiones, a las transformaciones napoleónicas, pero no pueden predicarse, sin más, de la época liberal, ni como conjunto, ni como suele convencionalmente entenderse, esto es, comprendida entre 1830 y 1880 , cuando comienza el ciclo de su declive. Así, si bien es cierto que con la revolución se instituye "una noción abstracta y universal de ciudadanía», desvinculando al individuo de los núcleos corporativos tradicionales que lo constituían jurídicamente, menos claro resulta que «el Derecho estatal se convierta en la principal 
forma de mediación social general de todas las relaciones» ya desde ese momento (Noguera, 2019, p. 18). El espacio dejado por la revolución a la autocomposición de los conflictos, a la conciliación y el arbitraje (Clavero, 1999) o a la autoadministración de las municipalidades (Mannori y Sordi, 2001, pp. 217 ss.) no permite sin más deducir esa «pan-juridificación» estatalista de la realidad social.

Puede por eso que, en una falta historiográfica habitual, se esté atribuyendo a la Revolución lo que corresponde, en realidad, a Napoleón. Este salto, de hecho, parece evidente en lo que hace a la creación de «la forma de colectividad adecuada para el desarrollo del capitalismo», con el predominio de la lógica contractualista en el ámbito privado (Noguera, 2019, p. 18). Poca duda cabe aquí de que no se debió a la Declaración de los derechos, sino al código, más concretamente al Code, la generalización en sociedad de los patrones de intercambio funcionales a la reproducción de la burguesía (Arnaud, 1973; Soboul, 1993, pp. 9 ss.). Y es que incluso la generalización del derecho de accesión sobre los frutos del trabajo por parte del propietario, en la que el autor halla la clave «de la alienación», fue aportación napoleónica (Clavero, 1998). Tal constatación habría ahorrado además al autor secundar el superficial razonamiento reaccionario según el cual el terror jacobino pondría en evidencia que la declaración de derechos de 1789, en realidad, «no tenía una función jurídica ni una preocupación protectora de derechos individuales», sino la económica de fundar el capitalismo (Noguera, 2019, p. 19).

No distinguiendo lo introducido por la Revolución y por Napoleón, tampoco puede el lector discernir cuándo, con su idea del «Derecho moderno» (Noguera, 2019, p. 68) o del «Espacio-tiempo histórico liberal» (Noguera, 2019, p. 25), se refiere a la cesura revolucionaria o al orden jurídico decimonónico. $Y$ no es una diferenciación secundaria, pues el segundo se irguió dando la espalda a una parte importante de la experiencia de 1789-1795. De hecho, su identidad característica procede de su antidemocratismo, de su rechazo visceral a la intervención del poder constituyente del pueblo y de su acerado elitismo.

Con esto quiere señalarse que, para caracterizar desde el derecho el marco histórico liberal, si por tal se considera el decimonónico y no el revolucionario inicial, no podemos entenderlo bajo ningún concepto como marcado, en el ámbito público, por concepciones contractualistas, por más relevantes que estas fuesen para regir los intercambios privados. Por el contrario, la iuspublicística europea dominante representó la base social del Estado en términos anticontractualistas y antiindividualistas (Costa, 1986, pp. 12 ss.), justo como dispositivo de prevención frente a cualquier desborde democrático. Es más, la idea prevalente de legitimidad del poder en época liberal no fue tanto «de origen», como el autor sostiene (Noguera, 2019 , p. 25), cuanto de fin o utilidad, en el entendido de que las leyes del Estado debían adecuarse para ser legítimas a una magnitud tan objetiva como la del «interés general» (Perrin, 2012). Se rehuía cualquier fundamentación voluntarista, que ligase la legitimidad de las decisiones públicas a la libre voluntad colectiva, por eso los representantes debían elegirse entre los «capaces» por encarnar otro factor objetivo como la «soberanía de la razón» (Rosanvallon, 1985).

De ahí que para el «liberalismo centrista» como forma cultural predominante en el siglo XIX (Wallerstein, 2016), el «fundamento de legitimación» del derecho en ningún caso residiese «en el hecho de emanar de instancias de representación democrática» (Noguera, 2019, p. 27). Y acaso tampoco pueda aseverarse que expropió sin más a los individuos de «su capacidad para la autoejecución comunitaria de derechos» (Noguera, 2019, p. 68). Esto es rigurosamente cierto en referencia a la liquidación de la sociedad corporativa del antiguo régimen, base de la que indudablemente partirá el Estado liberal. Ahora bien, el espacio dejado a la autonomía 
por el derecho burgués decimonónico, en cuanto se ensanchó dejando atrás las prohibiciones, exclusiones y discriminaciones clasistas, empezó a dejar espacio a la sindicación obrera, los socorros mutuos y otras iniciativas solidarias que, por uso de la tolerancia, comenzaron a proliferar en su interior. $Y$ en cuanto la cuestión social comenzó a alborear, las respuestas cooperativas espontáneas hasta encontraron respaldo institucional como vía de solución preferente ${ }^{9}$.

\section{3. ¿Narración o invención?}

El profesor Noguera sostiene que la «narrativa histórica» es una de las vertientes teóricas que nos permitiría superar «la ideología de la soberanía» (Noguera, 2019, p. 24). Por eso cuentan con un peso específico notable las representaciones historiográficas en el curso de su argumentación, pero, como se ha indicado, esa presencia obedece a motivaciones instrumentales más que cognitivas 0 investigadoras. Y la mirada del historiador no puede sino quedar insatisfecha ante el intento -quizá sobrante- de legitimar las propias posiciones en la historia.

Tal tentativa se hace especialmente visible al representar el «espacio comunitario preliberal» como un "derecho nacido del pueblo» donde se distingue «entre Derecho y Justicia», precisamente por atribuir preferencia a criterios materiales de equidad sobre los formales de la normatividad general (Noguera, 2019, p. 28). Esta forma de caracterizar "las múltiples formas preliberales de comunitarismo» obedece al propósito de presentar los «recientes y nuevos espacios de autogestión comunitaria» como sus «herederos» (Noguera, 2019, p. 27). Estamos ante un claro y comprensible intento de inscribir los movimientos de emancipación colectiva en una tradición más o menos consistente, pero su ejecución requiere demasiada imprecisión historiográfica.

El propio autor demuestra que lo sabe cuando afirma que «la comunidad servil medieval no debe ser idealizada como ejemplo de comunalismo» (Noguera, 2019, p. 133). Lo sorprendente es que, anotando la advertencia, incurra igual en la citada idealización. Con ella la «narrativa histórica» tiene mucho más de «narrativa» que de «histórica». Si no cabe proponerla es por una doble razón.

En primer lugar, las costumbres comunitarias protectoras de las capas humildes, la que Thompson llamase «economía moral»-en contraste con la "economía política» de signo liberal-, contaban con una cobertura cultural y religiosa, todavía hegemónica en el siglo XVIII, que comunicaba a sus requerimientos y limitaciones para con la libre competencia un grado razonable de obligatoriedad (Thompson, 2019). No existen hoy ni siquiera residuos de ese marco cultural precapitalista y cristiano a los que apelar para fundamentar el comunitarismo democrático presente. El discurso religioso que aún circula en la esfera pública se halla casi por entero instrumentalizado por la propiedad y los intercambios privados.

Por otro lado, los usos cooperativos y las prácticas comunales desplegados en torno a instituciones medievales como los bienes de propios o los mercados libres reflejan «la jerarquía de la sociedad estamental» (Keiser, 2020, p. 250), y no tanto, como el autor sugiere, prácticas en las que «el excedente» resulta «gestionado en

9 Las respuestas cooperativas para atajar la cuestión social eran, de hecho, las preferidas por los autores liberales de la belle époque, justo porque les permitía eludir el intervencionismo con técnicas de fomento indirecto (Martín, 2017, pp. 26 ss.). Se conoce también la inclinación conservadora por estatalizar las iniciativas obreras solidarias para hacerlas generalmente obligatorias (de ahí procede el origen de los famosos seguros sociales de Bismarck) o incluso por implantar sistemas de asistencia social, como ejemplifica el caso de la «socialización de las panaderías» citado en Los Buddenbrook (Mann, 2019, p. 429). 
común con vista a la reproducción de la comunidad» (Noguera, 2019, p. 27). En efecto, los «señores feudales habían decidido cómo era el reparto del uso de los derechos, cómo se organizaba, incluso, a veces, en su propio provecho» (Keiser, 2020 , p. 250), funcionalizando de ese modo los artefactos comunitarios.

Malamente podemos fundar pretensiones de autonomía en experiencias marcadas por la jerarquía. Cabalgar la tendencia histórica hacia el «neomedievalismo» siempre tiene el riesgo de que nos aboque al «neofeudalismo». Secundamos, desde luego, la idea de que los derechos humanos existen como «ideafuerza» que, sin estar "positivizada en el ordenamiento jurídico estatal, puede ser usada como herramienta discursiva y política sobre la que fundamentar determinadas acciones de contrapoder o autoejecución popular de derechos al margen del Derecho oficial» (Noguera, 2019, p. 67). De hecho, no cabe una historia de los derechos creíble sin una historia social de la lucha por los derechos que antecedió siempre a su consagración constitucional (Martín, 2014a). Sin embargo, resulta dudoso que esa lucha pueda encontrar hoy en el pasado «preliberal» antecedentes en los cuales reconocerse e inspirarse. Como se observa, solo puede hacerlo a costa de mutilarlo. Mucho mejor buscar esos antecedentes en las luchas emancipatorias de los pasados siglos XIX y XX, cuando el oponente a combatir era ya el capitalismo hoy desbordado.

Pero para volver la mirada a ese pasado liberal hay que problematizar el convencimiento de que, «en las Constituciones actuales, 1789 es el único punto de apoyo sobre el que se establecen y proyectan los paradigmas político-culturales universalistas» (Noguera, 2019, p. 132). No considero acertada tal aseveración, que juega en nuestro texto de condición de posibilidad para preferir la época medieval el marco histórico en el que encontrar las "otras tradiciones» con las que «complementar el paradigma político y jurídico-cultural de 1789 », instituyendo "un universalismo pluralista adecuado a la complejidad del nuevo tiempo» (Noguera, 2019, p. 132.).

Y no la considero certera porque el individualismo abstracto de los primeros tiempos revolucionarios se halla más que rectificado por la posterior historia constitucional. Encontramos en ella varios hitos constitutivos de un «constitucionalismo de los humildes» (Martín, 2016b) que tuvo en el reconocimiento de la pluralidad de los sujetos de derechos uno de sus aspectos más relevantes. 1793 y 1848 son fechas representativas de logros inolvidables en el reconocimiento de los derechos sociales y la democratización. 1919, 1931 y 1948 son a su vez años que encarnan conquistas inmarcesibles en la lucha por los derechos y la autonomía de los colectivos, al menos en lo que se refiere al territorio metropolitano. La presencia de estas efemérides convierte en más que problemático el hecho de que 1789 siga siendo, a día de hoy, no ya el único, sino el punto de referencia prevalente a la hora de sustentar culturalmente un universalismo emancipador. Es cierto que tampoco conviene contemplar estos hitos como puntos de llegada idealizados; conviene someterlos por igual a la crítica histórica, pero conforman, a mi entender, puntos de partida mucho más sugerentes y fructíferos para enriquecer o rectificar el constitucionalismo liberal desde posiciones que aspiren a la universalización de la dignidad que lo que pueda aportar cualquier intento de reconectar con el pasado preliberal. Además, tal reconexión impone una malformación del objeto representado que flaco favor hace a la historia constitucional. Y no olvidemos -Bourdieu medianteque no hay mejor forma de inspirar la acción política que haciendo ciencia -en este caso histórico-jurídica- rigurosa. 
Bibliografía

Adorno, Th. W. (2007). Teoría estética, Madrid: Akal.

Agüero, A. (2006). Las categorías básicas de la cultura jurisdiccional. En M. Lorente (coord.), De justicia de jueces a justicia de leyes: hacia la España de 1870. Madrid: CGPJ.

Arnaud, A.-J. (1973). Essai d'analyse structurale du code civile français: la règle du jeu dans la paix bourgeoise. París: LGDJ.

Bourdieu, P. (1966). La ideología jacobina. En Intervenciones 1961-2001. Ciencia social y acción política (pp. 70-78). Hondarribia: Hiru.

Bourdieu, P. (1975). Los intelectuales en las luchas sociales. En Intervenciones 19612001. Ciencia social y acción política (pp. 113-121). Hondarribia: Hiru.

Bourdieu, P. (1982). Desvelar los resortes del poder. En Intervenciones 1961-2001. Ciencia social y acción política (pp. 209-214). Hondarribia: Hiru.

Bourdieu, P. (1986). La negativa a ser carne de patrón. En Intervenciones 1961-2001. Ciencia social y acción política (pp. 259-267). Hondarribia: Hiru.

Bourdieu, P. (1989). Por una Internacional de los intelectuales. En Intervenciones 1961-2001. Ciencia social y acción política (pp. 322-334). Hondarribia: Hiru.

Bourdieu, P. (1992). Fundar la crítica sobre un conocimiento del mundo social. En Intervenciones 1961-2001. Ciencia social y acción política (pp. 297-305). Hondarribia: Hiru.

Bourdieu, P. (2000). La Europa social se estanca. En Intervenciones 1961-2001. Ciencia social y acción política (pp. 559-560). Hondarribia: Hiru.

Bourdieu, P. (2001a). Por una organización de resistencia al nuevo orden mundial. Intervenciones 1961-2001. Ciencia social y acción política (pp. 566-570). Hondarribia: Hiru.

Bourdieu, P. (2001b). Los investigadores y el movimiento social. En Intervenciones 1961-2001. Ciencia social y acción política (pp. 571-576). Hondarribia: Hiru.

Bourdieu, P. (2004). Intervenciones 1961-2001. Ciencia social y acción política, Hondarribia: Hiru.

Bourdieu, P. (2007). El neoliberalismo como revolución conservadora. En Intervenciones 1961-2001. Ciencia social y acción política (pp. 434-442). Hondarribia: Hiru.

Bourdieu, P. (2014). Sobre el Estado. Barcelona: Anagrama.

Castells, M. (2000). La era de la información. Economía, sociedad y cultura, Tomo II: El poder de la identidad. Madrid: Alianza.

Clavero, B. (1998). Les domaines de la propriété, 1789-1814: propiedades y propiedad en el laboratorio revolucionario. Quaderni Fiorentini, (27), pp. 269-378.

Clavero, B. (1999). La Pax et la Loi: ¿Absolutismo constitucional?. Anuario de historia del derecho español, (69), pp. 603-646.

Costa, P. (1986). Lo Stato immaginario. Metafore e paradigmi nella cultura giuridica italiana fra Ottocento e Novecento. Milán: Giuffrè.

Deleuze, G. (2017). Derrames. Entre el capitalismo y la esquizofrenia. Buenos Aires: Cactus.

Esteve Pardo, J. (2013). La nueva relación entre Estado y sociedad. Aproximación al trasfondo de la crisis. Madrid: Marcial Pons.

Fernández Buey, F. (2007). Prólogo. En S. Weil, Escritos históricos y políticos. Madrid: Trotta.

Ferrajoli, L. (1995). La sovranità nel mondo moderno. Nascita e crisi dello Stato nazionale. Milán: Anabasi.

Ferrajoli, L. (2018). Constitucionalismo más allá del Estado. Madrid: Trotta

Foucault, M. (1997). Arqueología del saber. Madrid: Siglo XXI. 
Foucault, M. (2002). El orden del discurso. Barcelona: Tusquets.

Hespanha, A. (1982). História das Instituições. Épocas medieval e moderna. Coímbra: Almedina.

Keiser, Th. (2020). El derecho de propiedad en la República de Weimar y en el fascismo. En S. Martín, F. Fernández-Crehuet y A. Aragoneses (eds.), Saberes jurídicos y experiencias políticas en la Europa de entreguerras. Sevilla: Athenaica.

Luhmann, N. (1998). Complejidad y modernidad: de la unidad a la diferencia. Madrid: Trotta.

Luhmann, N. y De Giorgi, R. (1999). Teoria della società. Milán: Franco Angeli.

Mann, Th. (2019). Los Buddenbrook. Decadencia de una familia. Barcelona: Edhasa. Mannori, L. y Sordi, B. (2001). Storia del diritto amministrativo. Roma-Bari: Laterza.

Martín, S. (2007). Penalística y penalistas españoles a la luz del principio de legalidad (1874-1944). Quaderni Fiorentini, I, (36), pp. 503-609.

Martín, S. (2009). Criminalidad política y peligrosidad social en la España contemporánea. Quaderni Fiorentini, (38), pp. 861-951.

Martín, S. (2011). El derecho político de la II República. Madrid: Dykinson.

Martín, S. (28 enero,2014a). Baracaldo, 1905: nuestra primera gran protesta antidesahucios. elDiario.es. Recuperado de https://www.eldiario.es/contrapoder/lucha-por-los-derechos-derecho-a-lavivienda 132 5072703.html

Martín, S. (20 febrero, 2014b). Sufragios, cooperación e inteligencia. elDiario.es. Recuperado de https://www.eldiario.es/contrapoder/sufragio-estrategiaelectoral $1325013308 . \mathrm{html}$

Martín, S. (4 mayo, 2016a). Historia y populismo. elDiario.es. Recuperado de https://www.eldiario.es/contrapoder/historia-populismo 132 4012532.html.

Martín, S. (2016b). El constitucionalismo de los humildes frente al constitucionalismo de los poderosos. Galde, (16), pp. 45-47.

Martín, S. (2017). Entre Weimar y Franco. Eduardo L. Llorens (1886-1943) y el debate jurídico de la Europa de entreguerras. Granada: Comares.

Martín, S. (2019). Notas sobre el régimen jurídico de los crímenes del franquismo. En J. Vallejo y S. Martín (coords.), En Antidora. Homenaje a Bartolomé Clavero (pp. 625-660). Navarra: Thomson Aranzadi.

Martín, S. (2020). Monarquía doctrinaria y republicanismo democrático en la crisis de la Restauración. En V. J. Vázquez y S. Martín (eds.), Monarquía y Constitución. Navarra: Thomson Aranzadi (en prensa).

Muschg, W. (2013). Epílogo del editor alemán. En A. Döblin, Berlín Alexanderplatz (pp. 51-70). Madrid: Cátedra.

Noguera, A. (2012). Utopía y poder constituyente. Los ciudadanos ante los tres monismos del Estado liberal. Madrid: Sequitur.

Noguera, A. (2014). La igualdad ante el fin del Estado social. Propuestas constitucionales para construir una nueva igualdad. Madrid: Sequitur.

Noguera, A. (2019). La ideología de la soberanía. Hacia una reconstrucción emancipadora del constitucionalismo. Madrid: Trotta.

Perrin, F. (2012). L'intérêt général et le libéralisme politique. Entre droits et intérêts particuliers (XVII-XIX siècles). París: F. Varenne.

Peukert, D. J. K. (2020). La Repubblica di Weimar. Anni di crisi della modernità classica (1985). Turín: Bollati Boiringhieri.

Polanyi, K. (2003). La gran transformación. Los orígenes políticos y económicos de nuestro tiempo. Ciudad de México: FCE.

Reich, W. (2020). Psicología de masas del fascismo. Madrid: Enclave de Libros.

Rosanvallon, P. (1984). La crise de l'Etat-providence. París: Seuil.

Rosanvallon, P. (1985). Le moment Guizot. París: Gallimard.

Rosanvallon, P. (2007). El modelo político francés. La sociedad civil contra el jacobinismo, de 1789 hasta nuestros días. Buenos Aires: Siglo XXI. 
Rügemer, W. (2013). Las agencias de calificación. Una introducción al actual poder del capital. Barcelona: Virus.

Soboul, A. (1993). La Francia de Napoleón. Barcelona: Crítica.

Streek, W. (2017). ¿Cómo terminará el capitalismo? Ensayos sobre un sistema en decadencia. Madrid: Traficantes de Sueños.

Teshke, B. (2011). The myth of 1648: class, geopolitics, and the making of modern international relations. Londres: Verso.

Thompson, E. P. (2019). Costumbres en común. Madrid: Capitán Swing.

Tuck, R. (1981). Natural rights theories: their origin and development. Cambridge: Cambridge University Press.

Vallejo, J. (2012). El príncipe ante el derecho en la cultura del ius commune. En M. Lorente y J. Vallejo (coords.), Manual de historia del derecho. Valencia: Tirant lo Blanch.

Wallerstein, I. (2006). El moderno sistema mundial. Tomo IV: El liberalismo centrista triunfante 1789-1914. Madrid: Siglo XXI.

Weil, S. (1933). Escritos históricos y políticos. Madrid: Trotta.

Weiss, P. (2003). La estética de la resistencia. Hondarribia: Hiru. 